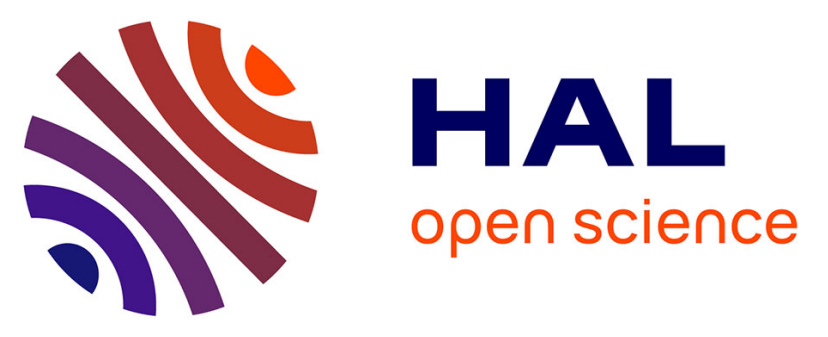

\title{
Development of Early-Warning Model for Intensive Pig Breeding
}

Nanxin Chen, Qingling Duan, Jianqin Wang, Ruizhi Sun

\section{To cite this version:}

Nanxin Chen, Qingling Duan, Jianqin Wang, Ruizhi Sun. Development of Early-Warning Model for Intensive Pig Breeding. 8th International Conference on Computer and Computing Technologies in Agriculture (CCTA), Sep 2014, Beijing, China. pp.616-626, 10.1007/978-3-319-19620-6_69 . hal01420279

\section{HAL Id: hal-01420279 \\ https://hal.inria.fr/hal-01420279}

Submitted on 20 Dec 2016

HAL is a multi-disciplinary open access archive for the deposit and dissemination of scientific research documents, whether they are published or not. The documents may come from teaching and research institutions in France or abroad, or from public or private research centers.
L'archive ouverte pluridisciplinaire HAL, est destinée au dépôt et à la diffusion de documents scientifiques de niveau recherche, publiés ou non, émanant des établissements d'enseignement et de recherche français ou étrangers, des laboratoires publics ou privés. 


\title{
Development of early-warning model for intensive pig breeding
}

\author{
${ }^{1}$ Nanxin Chen, ${ }^{1}$ Qingling Duan, ${ }^{1}$ Jianqin Wang, ${ }^{1}$ Ruizhi Sun \\ ${ }^{1}$ China Agricultural University, College of Information and Electrical Engineering, Beijing 100083, \\ China \\ (Received/Accepted: xxx)
}

\begin{abstract}
Following the rapid development of intensive pig breeding in China, the impact of environmental factors on the production and health of pigs has become increasingly apparent, and the monitoring of these environmental factors recognized as critical for improved breeding productivity. Based on the effects of environmental factors on pig growth, this paper established an early-warning model of the piggery environment. Using the model and the environmental factors, which were obtained in real time from a piggery, it was possible to obtain timely warning information, conducive to both creating an appropriate breeding environment for pigs and reducing the incidence of disease. In this article, we established the environmental early-warning indicators relating to pig breeding and then demonstrated the method based on single-factor and fuzzy comprehensive multi-factor models of the piggery environment. Finally, the two models were analyzed based on the experimental results, which showed that the fuzzy comprehensive early-warning model performed better than the single-factor model, and that it could be applied in an intensive farming environment to provide timely warning of environmental deterioration, to maintain the safety of the pig-breeding environment.
\end{abstract}

Keywords: environmental factor, single-factor early-warning model, fuzzy comprehensive early-warning model

\section{INTRODUCTION}

In China environmental factors are becoming increasingly important to the health and productivity of pigs because of the rapid development of pig breeding. As a result, control of the piggery environment has become a critical factor in improving the efficiency of pig breeding. The environmental factors and other elements that directly or indirectly affect the growth, development, reproduction, and health of livestock include temperature, humidity, noise, illumination, and harmful gases [1-3]. For example, high temperature 
can cause a pig to reduce its nourishment intake and thus affect its growth. In this article, we analyzed the effect of each selected environmental factor and based on the results, built an environmental early-warning model. According to environmental data acquired in real time, warning information could be delivered by the early-warning model, making it conducive to both creating an appropriate breeding environment for pigs and improving the efficiency of pig breeding.

At present, research on the breeding of livestock and poultry is concentrated mainly on the influence of different environmental factors on the growth of the animal [2-3] and on monitoring the breeding environment [4-7]. Hansen et al. adopted a model-based control design method to develop a controller to regulate the airflow of the breeding environment to control its inner temperature and humidity [8]. Soldato et al. used robust nonlinear feedback control and feed forward control of the inner temperature and humidity to maximize livestock productivity [9]. However, in the field of pig breeding, little research has been reported on early-warning models, especially studies of early-warning models combining multiple environmental factors. At present, common early-warning models can be divided into single and multi-factor models. Single-factor models always incorporate the theory of "certainty" in the index model, and establish the worst factor for the warning of the piggery environment by comparing various factors with early-warning standards [10]. The common feature of multi-factor early-warning models is the inclusion of techniques such as artificial neural networks, the N.L. Nemerow Index method, and fuzzy comprehensive evaluation methods. Warnings achieved using artificial neural networks are better, but require additional training data [11]. The N.L. Nemerow Index method, despite considering the most significant factors, cannot reflect the relative importance of the various factors [11]. A fuzzy comprehensive early-warning model is a relatively mature method used widely in water-quality prediction that can produce realistic results. It describes the warning level by membership degree in fuzzy mathematics, and then determines the weight of each factor, evaluates it, and generates the warning [12-14].

In this article, we selected five environmental factors as early-warning indicators for the pig-breeding environment, and designed four grades of environmental warning: suitable, mild warning, moderate warning, and severe warning. Then, we demonstrated the method based on single- and fuzzy comprehensive multi-factor models for the piggery environment, and an experiment was designed to validate the model.

\section{CONSTRUCTION OF EARLY-WARNING INDICATORS}

The factors that affect the pig-breeding environment are complex and they can act collectively or individually to affect the animals in many ways. The proper growth environment differs during every stage of development of the pigs and therefore the environmental indicators should be assessed according to the animals' growth characteristics and the corresponding environmental standards. In this article, we only consider environmental factors of standardized scale pig farms, and although fattening pigs serve as our source material, we do not consider the effects of feed.

At present, the national standards of environmental parameters regarding pigs are principally the "Standardization Construction Standard of Scale Pig Farms", and "Scale Farms Environmental Parameters and Environmental Management" $[15,16]$. According to the national standards and by consulting breeding experts, the principal environmental factors affecting pig breeding were determined to include temperature, humidity, harmful gases $\left(\mathrm{NH}_{3}, \mathrm{H}_{2} \mathrm{~S}\right.$, and $\left.\mathrm{CO}_{2}\right)$, dust, sunlight, noise, and airflow. Because intensive breeding occurs in buildings equipped with relatively complete facilities and relatively stable conditions of lighting, noise, dust, and airflow, we selected significant changes of temperature, humidity, and air pollutants as the environmental early-warning indicators. These factors could be divided into two categories: single threshold factors (STFs) and double threshold factors (DTFs). STFs include $\mathrm{NH}_{3}$, 
$\mathrm{H}_{2} \mathrm{~S}$, and $\mathrm{CO}_{2}$ because they are harmful to the pigs when their concentrations exceed certain standards. DTFs include temperature and humidity because values of these factors that are either too high or too low will affect the health of the pigs.
According to the environmental standards of pig breeding $[15,16]$, the grading standards of environmental warnings are as shown in Tables 1 and 2.

Table 1. STF early-warning grading standard

\begin{tabular}{ccccccccc}
\hline & Suitable & \multicolumn{2}{c}{ Mild warning } & \multicolumn{2}{c}{ Moderate warning } & \multicolumn{2}{c}{ Severe warning } \\
\cline { 3 - 8 } & & & low & high & low & high & low & high \\
\hline Temperature $\left({ }^{\circ} \mathrm{C}\right)$ & $15-23$ & $10-15$ & $23-30$ & $1-10$ & $30-35$ & $<1$ & $>35$ \\
Humidity(\%RH) & $65-75$ & $45-65$ & $75-80$ & $40-45$ & $80-95$ & $<40$ & $>95$ \\
\hline
\end{tabular}

Table 1. DTF early-warning grading standard (mg/m3)

\begin{tabular}{ccccc}
\hline & Suitable & Mild warning & Moderate warning & Severe warning \\
\hline $\mathrm{CO}_{2}$ & $<1500$ & $1500-7857$ & $7857-39285$ & $>39285$ \\
$\mathrm{NH}_{3}$ & $<25$ & $25-30$ & $30-35$ & $>35$ \\
$\mathrm{H}_{2} \mathrm{~S}$ & $<10$ & $10-30$ & $30-75$ & $>75$ \\
\hline
\end{tabular}

\section{CONSTRUCTION OF THE EARLY-WARNING MODEL}

\subsection{Single-factor early-warning model}

The single-factor early-warning model (SFM) is evaluated on single environmental factors of the piggery, and the worst factor taken as the indicator of the piggery environment.

The definition of the STF's early-warning index $I S_{i}$ is as follows:

$$
I S_{i}=\frac{C_{i}}{S_{i}}
$$

where $C_{i}$ is the measured value of environmental factor $i$ and $S_{i}$ is the standard value of environmental factor $i$; the value is exceeded when $I S_{i}>1$

For DTFs, the early-warning index $I D_{i}$ is defined as follows:

$$
\begin{aligned}
& \mathrm{ID}_{\mathrm{i}}=\frac{\mathrm{s}_{\mathrm{li}}-c_{i}}{s_{u i}-s_{l i}} \quad \mathrm{c}_{i}<s_{l i} \\
& \mathrm{ID}_{\mathrm{i}}=0 \quad \mathrm{~s}_{l i} \leq \mathrm{c}_{i}<s_{u i} \\
& \mathrm{ID}_{\mathrm{i}}=\frac{c_{i}-\mathrm{s}_{\mathrm{ui}}}{s_{u i}-s_{l i}} \quad \mathrm{c}_{i}>s_{u i}
\end{aligned}
$$

where $C_{i}$ is the measured value of environmental factor $i, S_{l i}$ is the standard low threshold of factor $i$, and $S_{u i}$ is the standard high threshold of factor $i$; the value is exceeded when $I D_{i} \neq 0$.

\subsection{Fuzzy comprehensive early-warning model}

The result of the SFM for the piggery reflects the effect of a single environmental factor only. However, the interaction of multiple environmental factors influences the growth of the pigs, and environmental quality is a fuzzy concept without clear boundaries for the effects of the factors. Therefore, this paper presents a fuzzy comprehensive early-warning model (FCM) for a piggery environment. 
In the FCM, a subjection degree matrix is initially established according to a set of subjection degrees for each environmental factor. Then, a comprehensive evaluation vector, which is the product of the subjection degree and weight of each environmental factor, is obtained. This vector reflects the subjection degree of the current environment belonging to each environmental early-warning grade [8].

(1) The subjection degree calculation of STF

This paper defined four warning grade standards: suitable, mild warning, moderate warning, and severe warning, which correspond to values of ' $j$ ' $=0,1,2$, and 3 , respectively, and designate the subjection degree function for each grade for each factor.

In this paper, $r s_{i j}$ denotes the subjection degree of the STF ' $i$ ' on the environmental standard grade ' $j$ '. The STF includes $\mathrm{NH}_{3}, \mathrm{H}_{2} \mathrm{~S}$, and $\mathrm{CO}_{2}$, which correspond to values of ' $i$ ' $=0,1$, and 2 , respectively. The subjection degree function is constructed using the following trapezoid formula.

The subjection degree function of grade 0 for the STF is defined as follows:

$$
\mathrm{rs}_{\mathrm{ij}}= \begin{cases}1 & \mathrm{C}_{\mathrm{i}} \leq S_{i 0} \\ \frac{S_{i 1}-C_{i}}{S_{i 1}-S_{i 0}} & S_{i 0}<C_{i} \leq S_{i 1} \\ 0 & C_{i}>S_{i 1}\end{cases}
$$

The subjection degree function of grade $j(j=1,2)$ is defined as follows:

$$
\mathrm{rS}_{\mathrm{ij}}= \begin{cases}0 & \mathrm{C}_{\mathrm{i}} \leq S_{i(\mathrm{j}-1)} \\ \frac{C_{i}-S_{i(\mathrm{j}-1)}}{S_{i \mathrm{j}}-S_{i(\mathrm{j}-1)}} & S_{i(\mathrm{j}-1)}<C_{i} \leq S_{i j} \\ \frac{S_{i(\mathrm{j}+1)}-C_{i}}{S_{i(\mathrm{j}+1)}-S_{i j}} & S_{i \mathrm{j}}<C_{i} \leq S_{i(\mathrm{j}+1)} \\ 0 & C_{i}>S_{i(\mathrm{j}+1)}\end{cases}
$$

The subjection degree function of grade 3 is defined as follows:

$$
\mathrm{rs}_{\mathrm{ij}}=\left\{\begin{array}{lc}
0 & \mathrm{C}_{\mathrm{i}} \leq S_{i 2} \\
\frac{C_{i}-S_{i 2}}{S_{i 3}-S_{i 2}} & S_{i 2}<C_{i} \leq S_{i 3} \\
1 & C_{i}>S_{i 3}
\end{array}\right.
$$

where $C_{i}$ is the measured value of the STF $I$ and $S_{i j}$ is the maximal value of the warning grade $j$ in the early-warning grading standard for the STF.

For instance, $S_{l j}=(0,10,30,75)$ are maximal values of each warning grade for $\mathrm{H}_{2} \mathrm{~S}$. We assume $C_{1}$ $=17 \mathrm{mg} / \mathrm{m}^{3}$; then, $R S_{1 j}=(0,0.65,0.35,0)$.

(2) The subjection degree calculation of DTF

For the DTF, this paper also defined four warning grade standards: suitable, mild warning, moderate warning, and severe warning. The warning grade of the environment is denoted by $|\mathrm{j}|=\{0,1,2,3\}$ and $\mathrm{j}$ $\in\{-3,-2,-1,0,1,2,3\}$. If the measured value is bigger than the maximal value of grade 0 , then $j=\{0$, $1,2,3\}$; otherwise, $\mathrm{j}=\{-3,-2,-1,0\}$.

In this paper, $r d_{i j}$ denotes the subjection degree of the DTF ' $i$ ' on the environmental warning grade ' $j$ '. The DTF includes temperature and humidity, which correspond to values of ' $i$ ' $=0$ and 1 , respectively. The subjection degree function is constructed using the following trapezoid formula.

The subjection degree function of grade -3 for the DTF is defined as follows:

$$
\mathrm{rd}_{\mathrm{ij}}=\left\{\begin{array}{lc}
1 & \mathrm{C}_{\mathrm{i}} \leq S_{i(-3)} \\
\frac{S_{i(-2)}-C_{i}}{S_{i(-2)}-S_{i(-3)}} & S_{i(-3)}<C_{i} \leq S_{i(-2)} \\
0 & C_{i}>S_{i(-2)}
\end{array}\right.
$$

The subjection degree function of grade $j(j=-2$, $-1,0,1,2)$ is defined as follows: 


$$
\operatorname{rd}_{\mathrm{ij}}= \begin{cases}0 & \mathrm{C}_{\mathrm{i}} \leq S_{i(\mathrm{j}-1)} \\ \frac{C_{i}-S_{i(\mathrm{j}-1)}}{S_{i \mathrm{j}}-S_{i(\mathrm{j}-1)}} & S_{i(\mathrm{j}-1)}<C_{i} \leq S_{i j} \\ \frac{S_{i(\mathrm{j}+1)}-C_{i}}{S_{i(\mathrm{j}+1)}-S_{i j}} & S_{i \mathrm{j}}<C_{i} \leq S_{i(\mathrm{j}+1)} \\ 0 & C_{i}>S_{i(\mathrm{j}+1)}\end{cases}
$$

The subjection degree function of grade 3 is defined as follows:

$$
\mathrm{rd}_{\mathrm{ij}}=\left\{\begin{array}{lc}
0 & \mathrm{C}_{\mathrm{i}} \leq S_{i 2} \\
\frac{C_{i}-S_{i 2}}{S_{i 3}-S_{i 2}} & S_{i 2}<C_{i} \leq S_{i 3} \\
1 & C_{i}>S_{i 3}
\end{array}\right.
$$

where $C_{i}$ is the measured value of the DTF $i$ and $S_{i j}$ is the maximal value of the warning grade $j$ in the early-warning grading standard for the DTF.

For instance, $S_{0 j}=(1,10,15,19,23,30,35)$ are maximal values of each warning grade for temperature. We assume $C_{0}=27{ }^{\circ} \mathrm{C}$; then, $\mathrm{RD}_{0 \mathrm{j}}=(0$, $0.43,0.57,0)$.

(3) The calculation of weight

In this paper, $W=\left[w_{0}, w_{1}, w_{2}, w_{3}, w_{4}\right]$ denotes the weight of each factor. Considering that environmental factors that have higher warning grades or that have more serious effects on the pigs should have greater weight, the method of calculating the weight was designed as follows.

(i) According to the influence of environmental factors on the pigs, this paper designed the initial weights as follows:

$$
w_{b}=\{0.07,0.06,0.07,0.11,0.09\}
$$

(ii) The remaining 0.6 of the weight is distributed according to the severity of each factor.

In this paper, $z_{i}$ denotes the severity of the environmental factor.

For STFs:

$$
\mathrm{z}_{\mathrm{i}}=\frac{c_{\mathrm{i}}-b_{i}}{s_{i}-b_{i}}
$$

\section{For DTFs:}

when the monitoring value is higher than the suitable value:

$$
\mathrm{z}_{\mathrm{i}}=\frac{c_{\mathrm{i}}-s_{u i}}{s_{i}-b_{i}}
$$

and when the monitoring value is lower than the suitable value:

$$
\mathrm{z}_{\mathrm{i}}=\frac{s_{\mathrm{li}}-c_{i}}{s_{i}-b_{i}}
$$

In the formula, $z_{i}$ means the $i$-th factor's weight, $c_{i}$ is the measured value of the $i$-th factor, $s_{i}$ is the maximum of grade $j$ of the warning grading standard, and $b_{i}$ is the minimum of grade $j$ of the warning grading standard.

The weight of each factor is calculated as follows:

$$
w_{i}=\frac{z_{i}}{\sum_{j} z_{j}} \times 0.6+w_{b j}
$$

where $w_{b i}$ is the base weight of the $i$-th factor.

(4) The calculation of the early-warning grade

Using the methods stated earlier, we can obtain a subjection degree matrix $R$ that consists of a subjection degree for each grade of each factor, and the fuzzy comprehensive warning vector is the product of the weight vector $W$ and the subjection degree matrix $R$.

The subjection matrix $R$ is calculated as follows:

$$
R=\left[\begin{array}{llll}
r s_{00} & r s_{01} & r s_{02} & r s_{03} \\
r s_{10} & r s_{11} & r s_{12} & r s_{13} \\
r s_{20} & r s_{21} & r s_{22} & r s_{23} \\
r d_{00} & r d_{0 x_{1}} & r d_{0 x_{2}} & r d_{0 x_{3}} \\
r d_{10} & r d_{1 x_{1}} & r d_{1 x_{2}} & r d_{1 x_{3}}
\end{array}\right]
$$


In the formula, $(x 1, x 2, x 3)$ could be $(1,2,3)$ or $(-1,-2,-3)$

Then, the fuzzy comprehensive warning vector $B$ is calculated as follows:

$$
B=W \times R
$$

Finally, we calculated the grade of fuzzy comprehensive evaluation as follows:

$$
I=b_{1} \times 1+b_{2} \times 2+b_{3} \times 3+b_{4} \times 4
$$

When the result matches:

$0 \leq I<1$, the warning grade is 1 ;

$1 \leq I<2$, the warning grade is 2 ;

$2 \leq I<3$, the warning grade is 3 ;

$3 \leq I$, the warning grade is 4 .

\section{WARNING PROCESS}

Based on the early-warning model stated earlier, this paper designed an environmental warning process, as shown in Figure 1.

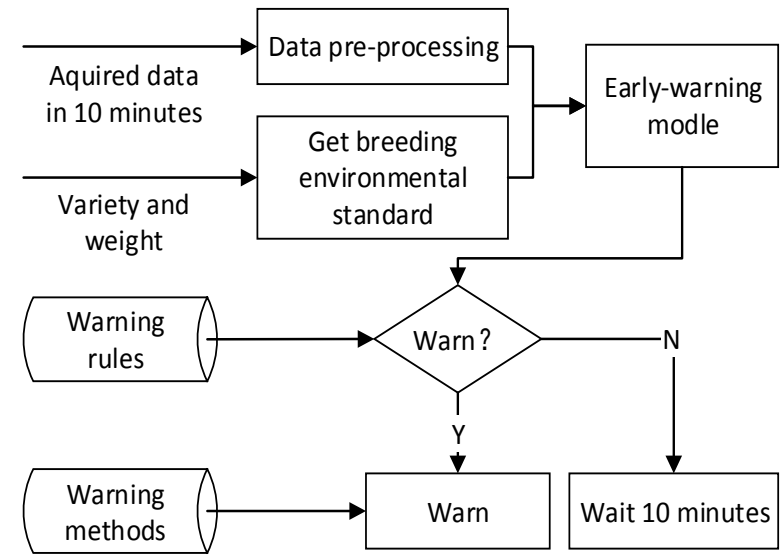

Fig. 1. The warning process

The detail of the warning process is as follows:

(1) Search the breeding environmental standard from the breeding information library according to the pigs' breed and weight;

(2) Every 10 minutes, data from the sensors are filtered using the Distribution method [17], and the average of these data calculated to evaluate the environment during that 10-minute interval using the early-warning model;

(3) Check whether a warning is required according to the evaluation results. If a warning is not needed, wait another 10 minutes and return to step (2); otherwise, choose the appropriate warning from the warning method database according to the evaluated result.

\section{EXPERIMENT AND ANALYSIS OF RESULTS}

We installed a set of sensors of environmental parameters at an experimental station in Zhuozhou. The parameters monitored included $\mathrm{NH}_{3}, \mathrm{CO}_{2}, \mathrm{H}_{2} \mathrm{~S}$, temperature, and humidity. We chose four periods for taking the experimental measurements, as shown in Table 3 (Temp is temperature, Hum is humidity, and the units of $\mathrm{NH}_{3}, \mathrm{CO}_{2}, \mathrm{H}_{2} \mathrm{~S}$, Temp, and Hum are $\mathrm{mg} / \mathrm{m}^{3}, \mathrm{mg} / \mathrm{m}^{3}, \mathrm{mg} / \mathrm{m}^{3},{ }^{\circ} \mathrm{C}$ and $\% \mathrm{RH}$, respectively), and the warning results of the SFM and FCM are shown in Table 4.

\begin{tabular}{|c|c|c|c|c|}
\hline No. & Date & Time & Factor & Value \\
\hline \multirow[t]{5}{*}{1} & 2013-11-15 & $22: 05: 36$ & $\mathrm{NH}_{3}$ & 0 \\
\hline & & $\sim$ & $\mathrm{CO}_{2}$ & 1288.5 \\
\hline & & $23: 05: 36$ & $\mathrm{H}_{2} \mathrm{~S}$ & 0 \\
\hline & & & Temp & 24.8 \\
\hline & & & Hum & 22.5 \\
\hline \multirow[t]{5}{*}{2} & 2013-11-17 & 03:05:36 & $\mathrm{NH}_{3}$ & 5 \\
\hline & & $\sim$ & $\mathrm{CO}_{2}$ & 35274 \\
\hline & & 04:05:36 & $\mathrm{H}_{2} \mathrm{~S}$ & 0 \\
\hline & & & Temp & 20.2 \\
\hline & & & Hum & 41 \\
\hline \multirow[t]{5}{*}{3} & $2013-11-18$ & $00: 05: 36$ & $\mathrm{NH}_{3}$ & 4.8 \\
\hline & & $\sim$ & $\mathrm{CO}_{2}$ & 2860.1 \\
\hline & & 01:05:36 & $\mathrm{H}_{2} \mathrm{~S}$ & 0 \\
\hline & & & Temp & 20 \\
\hline & & & Hum & 42.4 \\
\hline \multirow[t]{5}{*}{4} & $2013-11-25$ & $14: 05: 36$ & $\mathrm{NH}_{3}$ & 0 \\
\hline & & $\sim$ & $\mathrm{CO}_{2}$ & 2719.2 \\
\hline & & $15: 05: 36$ & $\mathrm{H}_{2} \mathrm{~S}$ & 0.8 \\
\hline & & & Temp & 20.8 \\
\hline & & & Hum & 39.2 \\
\hline
\end{tabular}

Table 3. Measured values 
Table 4. Warning results of SFM and FCM

\begin{tabular}{ccc}
\hline No. & SFM & FCM \\
\hline 1 & 4 & 4 \\
2 & 3 & 4 \\
3 & 3 & 3 \\
4 & 4 & 3 \\
\hline
\end{tabular}

We can draw several conclusions from the experimental results.

(1) In No. 1, the result of the FCM is grade 4, which is the same as the result of SFM. As can be seen from Table 3 , in No. 1 , the humidity is very low and the temperature is outside the optimum range; therefore, the warning results are appropriate to the actual situation.

(2) In No. 2, the result of the FCM is grade 4, but in No. 3, it is grade 3, whereas the result of the SFM is grade 3 in both. As can be seen from Table 3, the concentration of $\mathrm{CO}_{2}$ in No. 2 is obviously higher than in No. 3; therefore, the results obtained by the FCM are most reasonable.

(3) In No. 4, the result of the FCM is grade 3, while the result of the SFM is grade 4. As shown in Tables 3 and 1, in No. 4, humidity is $39.2 \%$, which is a little lower than the threshold $(40 \%)$, but the other environmental factors are very good. Considering all factors, a grade 3 warning is deemed most suitable based on the actual situation.

\section{CONCLUSIONS}

The main contributions of this paper are as follows:

(1) Many environmental factors affect the breeding and growth of pigs, but not all have a significant impact. This paper consulted authoritative environmental standards and considered the environmental factors of temperature, humidity, $\mathrm{CO}_{2}$, $\mathrm{NH}_{3}$, and $\mathrm{H}_{2} \mathrm{~S}$ as the principal factors for an early-warning model. The experimental results show that these factors satisfactorily reflect the actual situation of a pig-breeding environment.

(2) This paper compared a single-factor early-warning model with a fuzzy comprehensive early-warning model. The result of the experiment shows that when one or more factors exhibit significant deterioration, both models are able to describe the degree of deterioration of the environment accurately. However, when no single factor is seriously deteriorated, the performance of the fuzzy comprehensive early-warning model is superior to the single-factor early-warning model.

(3) The warning model presented in this paper is shown to perform well and therefore it could act as a timely warning of environmental deterioration.

\section{ACKNOWLEDGEMENTS}

This paper was supported by the National High Technology Research and Development Program (863 Plan) (2013AA102306), and the National Science and Technology Supporting Plan Project (2012BAD35B06), and the Program of International S\&T Cooperation(2013DFA11320).

\section{REFERENCES}

1. Feng Li. The impact of light on the pig and the lighting control technology[J]. Veterinary Journals of China Animal Husbandry, 2012(12).

2. Cheng Yang, Changchun Xu. Effect of environmental condition on reproductive performance of swine[J]. Heilongjiang Journal of Animal Reproduction, 2012(03).

3. Junmei Qu, Jinhui Niu. Study on the effect of different environmental factors on the growth of piglets[J]. Feed Review, 2005(03)

4. Longxia Sun. Design of livestock environment monitoring system[D]. Nanjing Agricultural University, 2011.

5. Yu, Xiao. Study on multi-environment factor monitoring system of the livestock breeding[J]. Sensors and Transducers, 2013(11).

6. Liangliang Gao, Daoliang Li. Study on the construction and management of the Internet of things application system of aquaculture supervisory[J]. Shandong Agricultural Sciences, 2013(08).

7. Sun Z. Design of a telemonitoring system for data acquisition of livestock environment[C]. Livestock Environment VIII - Proceedings of the 8th International Symposium, 2008.

8. Hansen, M. Temperature and humidity control in livestock stables[C]. 11th International Conference on Control, Automation, Robotics and Vision, ICARCV 2010, 2010. 
9. Soldatos, AG. Nonlinear robust temperature-humidity control in livestock buildings[J]. Computers and Electronics in Agriculture, 2005(03).

10. Zhen Ma. Study ofwater quality early warning model for Litopenaeus vannamei intensive aquaculture[D]. Ocean University of China, 2010.

11. Leilei Yang, Wenxi Lu. The application of improved N.L.Nemerow index method and fuzzy comprehensive method in water quality assessment[J]. Water Resources and Power, 2012(06).

12. Xiaoguang Li, Qiwen Zhou, Lei Zhang. The application of fuzzy comprehensive assessment of heavy metal pollution in the soil onfarmland which irrigationwith swine breeding wastewater $[\mathrm{J}]$. Journal of Agro-Environment Science, 2009(03).

13. Menghong Li. Heavy metal pollution in soil and the evaluation of farmland[D].Shandong Agricultural University, 2009.

14. Ruimei Wang, Youyuan He, Zetian Fu.Quality early warning model of pond water for freshwater aquaculture [J]. Journal of Jilin Agricultural University, 2011(01).

15. GBT 17824.3-2008, Scale farms environmental parameters and environmental management[S].

16. NYT 1568-2007, Standardization construction standardized of scale pig farms[S].

17. Zhuojun Xia. Application of distribution method in the treatment ofmistake errors[J]. Practical Measurement Technology, 2002(02). 